\title{
71. Perulu yazar José María Arguedas'ın Los Rios Profundos başlıklı romanında melez kimliğin yeniden oluşturulma çabası ${ }^{1}$
}

\section{Olcay ÖZTUNALI²}

APA: Öztunalı, O. (2021). Perulu yazar José María Arguedas'ın Los Rios Profundos başlıklı romanında melez kimliğin yeniden oluşturulma çabası. RumeliDE Dil ve Edebiyat Araştırmaları Dergisi, (24), 1211-1220. DOI: 10.29000/rumelide.996919.

\section{$\ddot{O} \mathbf{z}$}

Perulu yazar José María Arguedas, Latin Amerika neo-yerli edebiyatın en önemli temsilcilerinden biri olarak kabul edilir. 1958 yılında yayımlanan Los Ríos profundos başlıklı romanı yazarın üçüncü kitabıdır. Bu Romanında Arguedas, Peru toplum yapısının temelini oluşturan 'yerli' ve 'beyaz' kültürlerin farklılıklarını, ben anlatıcısı melez bir çocuk olan kahramanın yaşam öyküsü üzerinden anlatır: çocuk kahraman Ernesto'nun Cusco'da başlayan hikayesi, Abacay'da bir Hristiyan okulunda devam eder. Bu okulda Ernesto'nun aldığı derin zihinsel, duygusal ve ruhsal yaralara tanık oluruz. Çünkü bu okula başlayıncaya kadar içinde yetiştiği yerli kültürde söz konusu üç unsur birbiriyle uyum içindedir; her biri diğerini tamamlar. Oysa 'beyaz' adamın getirdiği Avrupa kültürü 'dualite' ye dayanır. $\mathrm{Bu}$ ön kabul de içindeki evrensel birlik duygusunu ve aynı ölçüde dış gerçeklikle olan ilişkisini zedeler. Bilindiği gibi, Arguedas'ın bu romanının ana eksenini belirleyen melez kimlik, yazarın kendi hayatının da bir gerçeğidir. Söz konusu kimlik tıpkı Peru’nun coğrafi yapısını oluşturan zıtlıklar gibi kendi içinde kültürel zıtlıklar barındırır: nasıl ki Peru coğrafyası temelde yerli kültürü yaşatan dağ kültürü ve Avrupa kültürünü yaşatan kıyı kültürü olarak ikiye ayrıldıysa, José Maria Arguedas'ın melez kimliğini de bu iki kültürel coğrafya oluşturur, tıpkı romanın kahramanı Ernesto gibi. Her ikisinde de melez kültürü oluşturan temel zıtlıkların başında dil gelir: dağ kültüründe, Peru'nun yerli dili olan Quechua konuşulurken, kıyı kültüründe İspanyolca konuşulur. Dil kuşkusuz konuşmanın ötesinde, gerçekliği algılama değerlendirme biçimidir. Bu düzlemde, Ernesto'nun yaşamsal deneyimlerinin bireysel bir tarih olarak ele alınacağı çalışmamız, Arguedas'ın da Ernesto üzerinden işlediği 'melezlik durumunu'nu kültürel anlamda yeniden oluşturma çabasına bir yaklaşım olacaktır. Bunu yaparken öncelikle, melez kimliği oluşturan temel unsurlar belirlenecek, bu unsurların birbirleri ile olan ilişkileri ve çatışmaları saptanacak, son olarak olası çözümler üzerine durulacaktır. Çalışmamızın çıkış noktasını Los rios profundos romanı, aynı zamanda bir antropolog da olan José María Arguedas'ın kendi düşünceleri ile yazar üzerine uzmanlaşmış Latin Amerikalı araştırmacıların çalışmaları oluşturacaktır.

Anahtar kelimeler: José María Arguedas, Los ríos profundos, Peru Edebiyatı, neo-indigenismo

23-24 2019 tarihinde Ankara'da gerçekleșen 2nd International Congres son Multidisciplinary Social Science (ICMUSS 2020) kongresinde sunulan "The Universal Unity and A Children's Toy "Zumbayllu" in the Novel Los Rios profundos" başlıklı bildiriden geliştirilerek yazılmıștır.

Dr. Öğr. Üyesi, İstanbul Medeniyet Üniversitesi, Edebiyat Fakültesi, İspanyol Dili ve Edebiyatı (İstanbul, Türkiye), suristan@yahoo.com, ORCID ID: oooo-0oo1-8565-5863 [Araştırma makalesi, Makale kayıt tarihi: 26.08.2021-kabul tarihi: 20.09.2021; DOI: 10.29000/rumelide.996919]

Adres | Address

RumeliDE Dil ve Edebiyat Araştırmaları Dergisi Osmanağa Mahallesi, Mürver Çiçeği Sokak, No:14/8 Kadıköy - ISTANBUL / TÜRKIYE 34714 e-posta: editor@rumelide.com

RumeliDE Journal of Language and Literature Studies Osmanağa Mahallesi, Mürver Çiçeği Sokak, No:14/8

Kadıköy - ISTANBUL / TURKEY 34714 tel: +90 $5057958124,+902167730616$

e-mail: editor@rumelide.com

phone: +90 5057958124 , +90 2167730616 


\title{
The attempt to re-create mixed race identity in the novel Los Rios Profundos by the Peruvian author José María Arguedas
}

\begin{abstract}
Peruvian author José María Arguedas is considered to be one of the leading writers of the neoindigenismo literature in Latin America. In his third novel Los Ríos profundos published in 1958, Arguedas portrays the differences between the 'indigenous' and 'white' cultures through the life story of a mixed race boy named Ernesto, the main protagonist of the novel. Starting in Cusco, Ernesto's story continues in Abacay at a Christian school. As readers, we witness the deep wounds inflicted on Ernesto's mind, soul and emotions. These three elements are in harmony and complementary of each other in the indigenous culture that Ernesto is brought up with prior to his schooling. The European culture that is brought by the 'white' man, on the other hand, is based on 'duality.' This presupposition damages Ernesto's sense of universal wholeness as well as his relationship with outer reality. As known, the mixed race identity, which determines the central axis of the novel, also coincides with the reality of Arguedas's life. This type of identity houses cultural dichotomy paralelling the contrasts contained in Peru's topography. The Peruvian geography is split into two cultures: the indigenous culture that lives high in the mountains and the European culture that lives by the sea. José Maria Arguedas's identity as a mixed race person also contains two cultural climates, very much like the novel's protagonist, Ernesto's. In both cases, among the many contradictions that form the mixed race culture, language is a primary one. In the mountains Quechua, the native language of Peru, is spoken, whereas in the culture of the sea, Spanish is used. Beyond communication, language is certainly a way of perceiving and evaluating reality. Along this line, taking Ernesto's lived experience as a micro history, this paper offers a perspective on Arguedas's depiction of 'the condition of mixed race through the character of Ernesto in his attempt to recreate it on the cultural level. In doing so, firstly the main components of the mixed race identity are identified, then the relationships and conflicts of these elements with each other are determined, and lastly potential resolutions are offered. In addition to the novel Los ríos profundos as the primary source, the own thoughts of José María Arguedas (he was also an anthropologist) and secondary sources such as articles on Arguedas written by Latin American scholars are utilized.
\end{abstract}

Keywords: José María Arguedas, Los ríos profundos, Peruvian Literature, neo-indigenismo

\section{Giriş}

Perulu yazar José María Arguedas, Latin Amerika neo-yerli edebiyatın en önemli temsilcilerinden biri olarak kabul edilir. 1958 yılında yayımlanan Los Ríos profundos başlıklı roman yazarın üçüncü kitabıdır. Bu romanında Arguedas, Peru toplum yapısının temelini oluşturan 'yerli' ve 'beyaz' kültürlerin farklılıklarını, ben anlatıcısı bir çocuk olan kahramanın yaşam öyküsü üzerinden anlatır: çocuk kahraman Ernesto'nun Cusco'da başlayan hikayesi, Abancay'da bir din okulunda devam eder. Bu okulda Ernesto'nun aldığı derin zihinsel, duygusal ve ruhsal yaralara tanık oluruz. Çünkü okula başlayıncaya kadar içinde yetiştiği yerli kültürde söz konusu üç unsur birbiriyle uyum içindedir; her biri diğerini tamamlar. Oysa 'beyaz adam'nn getirdiği Avrupa kültürü 'dualite’ ye dayanır. Bu ön kabul de içindeki evrensel birlik duygusunu ve aynı ölçüde dış gerçeklikle olan ilişkisini zedeler. Bu düzlemde, Ernesto'nun yaşamsal deneyimlerinin bireysel bir tarih olarak ele alınacağı çalışmamız, Arguedas'ın Ernesto üzerinden işlediği 'melezlik durumunu'nu kültürel anlamda yeniden oluşturma çabasına bir yaklaşım olacaktır. Bunu yaparken öncelikle, melez kimliği oluşturan temel unsurlar belirlenecek, bu

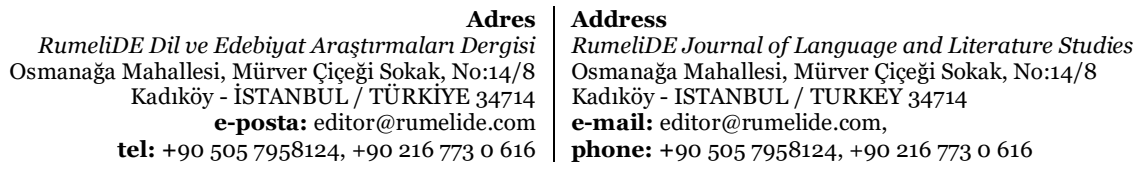


unsurların birbirleri ile olan ilișkileri ve çatışmaları saptanacak, son olarak da olası çözümler üzerine durulacaktır. Çalışmamızın çıkış noktasını Los ríos profundos romanı, aynı zamanda bir antropolog da olan José Marīa Arguedas'ın kendi düşünceleri ile yazar üzerine uzmanlaşmış Latin Amerikalı araştırmacıların makaleleri oluşturacaktır.

Roman 1920'li yıllarda geçer. Cuzco'da başlayan hikaye, Ernesto’nun beraber bir kaç şehirde dolaştıktan sonra babasından ayrılıp Abancay'da dini bir yatılı okula başlamasıyla devam eder. Ernesto'nun ergenlik döneminde bu okulda yaşadığı, tanık olduğu olaylar ve durumlar karşısındaki duyguları ile, her ikisine de dahil olduğu, yerli ve beyaz kültürü kendi içinde muhakeme etme sürecinden sonra şehirden ayrılışıyla sonlanır.

José Maria Arguedas'ın bu romanının ana eksenini belirleyen melez kimlik, yazarın kendi hayatının da bir gerçeğidir. Söz konusu kimlik tıpkı Peru'nun coğrafyasını oluşturan zıtlıklar gibi kendi içinde kültürel zıtlıklar barındırır: nasıl ki Peru coğrafyası temelde yerli kültürü yaşatan dağ kültürü ve Avrupa kültürünü yaşatan kıyı kültürü olarak ikiye ayrıldıysa José María Arguedas'ın melez kimliğini de tıpkı romanın kahramanı Ernesto gibi, bu iki kültürel coğrafya oluşturur. Melez kültürü oluşturan, her ikisinin de yaşadığı, temel çatışmaların başında 'dil' gelir: dağ kültüründe, Peru'nun yerli dili olan Quechua konuşulurken, kıyı kültüründe İspanyolca konuşulur. Dil kuşkusuz konuşmanın ötesinde gerçekliği algllama değerlendirme biçimidir.

Çocuk kahraman Ernesto roman boyunca bu iki algı arasındaki farkı anlayı anlamlandırmaya çalışırken, Arguedas, bir yetişkin melez ve üstelik de bir yazar olarak her iki algıyı öğrenip bilip netleştirdiğinde ve yazma işine koyulduğunda, bu eylemle birlikte aslında kendi içinde çözüldüğünü düşündüğü zorlu bir süreci yeniden yapılandırdığını fark eder. Çünkü, yerli kökeni nedeniyle, ana dili olan Quechua dilinde düşünüp İspanyolca yazması beklenmektedir. Üstelik bütünüyle farklı bir vizyona sahip yerli ruhunu Batı kültürü normlarında ifade edebilmek zorlu bir uğraştır. Kaldı ki Quechua dilinde gelişen kültür sözel bir kültürdür.

Nelson Osorio Tejada'nın da vurguladığı gibi, bu kültürde işitsel olan görsel olandan ya da müzikal olandan ayrılmaz, çünkü her şeyin bütünleyici bir ifadesi vardır ve bu bütünlük yazıya indirgenemez çünkü yazı şiirsel iletişimin sadece sözel yanını kaydeder (Tejada, 2012: 78).

Bu duruma karşın, genel olarak sözel kültürün yazılı kültüre geçerken kaybettiklerinden - dolayısıyla insana kaybettirdiklerinden çok- yazılı kültürde olup da sözel kültürde olmayandan yola çlkarak kıyaslama yapmaya alışkın rasyonel düşünce, birinin karşısında diğerini küçümseme eğilimindedir. Gustavo Martīnez "Espacio, identidad y memoria en Los Rīos profundos de J. M. Arguedas” başlıklı makalesinde bu durumu, "yenilmişlerin konuştukları dil de aynı yenilgilere ve konuşmacılarıyla aynı aşağılanmalara maruz kalır. Ve hala hayatta olmalarına rağmen, seslerini duyuramazlar. Tarih, hepimizin bildiği gibi, her zaman seçici sağırlıkla karakterize edilmiştir" cümleleriyle ifade ediyor (Martinez, 2008-2009: 46).

Arguedas bütün yaşamı ve yazın hayatı boyunca dil'de başlayan, dil ile başlayan kültürel bütünlügün peşindedir. Yaşamında deneyimlediğini, yazınında 'duyurmak' ister. Ancak bunu gerçekleştirmede en temel engelin kültürler arası hiyerarşi olduğunu bildiğinden iletişim içinde olan her bir kültürün kendini ifade edebileceği bir zemin oluşturulması gereğinin farkındadır.

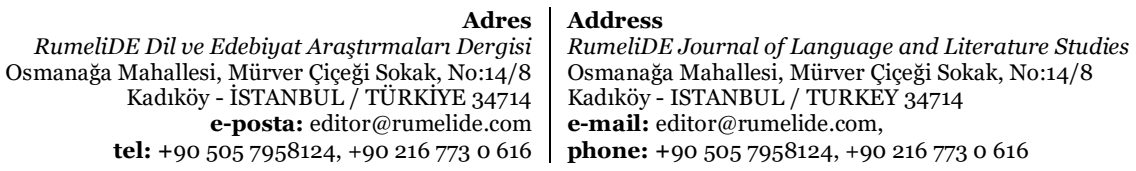


"El indigenismo en el Peru" başlıklı makalesinde, Peru'da gerçekleştirilen entegrasyon sürecini açlklarken, bu işlemin Hispanik kültürün yerli ve melez kültürden daha değerli olduğu ön kabulüne dayandırıldığının altını çizer: Peru'da entegrasyondan söz edildiğinde, sürekli olarak geleneksel yerli kültüründen Batı kültürüne doğru bir tür 'kültürlenme' nin akla geldiğini; aynı şekilde okuryazarlıktan söz edilirken de, İspanyolca dilinde okuma yazma öğrenmenin hedeflendiğini belirtirken, gerçek entegrasyonun İnka kütürünün birçok özelliğini koruyan, yaşayan Hispanik-Quechua kültürünü de içene alacak şekilde düzenlenmesi gerektiğini vurgular. Burada Arquedas'ın üzerinde durduğu, zamanın dışında, mitleşmiş bir İnka kültürü ve onun artık güncel olmayan değer ve geleneklerinin yeniden canlanması değil, hala var olan, toplumsal yaşantıda yer bulan değerlerin, ritüellerin, geleneklerin varlığının kabulüdür; bu kabul olmazsa iki kültürün birbirini anlayarak doğal ve sağlıklı bir biçimde entegre olması olanaklı değildir. Ancak diğer taraftan, 'yerli’ve 'beyaz' kültürün de kendi içinde değiştiğini, dönüştüğünü kabul etmek gerekir. Kültürler de diller ve toplumlar gibi doğal bir değişime uğrarlar. Bu yüzden göz ardı edilmemesi gereken, yaşamın doğal akışı içinde var olan unsurların yok sayılmadan kamu alanında yaşatılmasıdır. Diğer pek çok makalesinde olduğu gibi, Arguedas, farklı unsurları var sayarken hedeflenenin homojen bir kültür olmadığını belirterek, makalesini, Quechua dilinin Peru'nun ikinci resmi dili olacağına yönelik inancını ifade ederek bitirir (Arguedas:1967, 11-12).

Melez kimlik bu romanda Ernesto figürü ile bir hayatı anlamlandırma, içini doldurma mücadelesine dönüşür: roman boyunca onun kültürel kimlik arayışına ve ruhunun bu yolda aldığı yaralara tanık oluruz. Melez kimliğin hem beyaz hem yerli olma durumu ona özel, farklı hassasiyetler yaratır. Çünkü birbirleriyle mücadele eden iki kültüre birden aidiyet, hem varlı̆̆ını bir parçası olduğu için ikisini birden reddedememeyi, hem de birini diğerinin algısıyla da yorumlayabildiği için her ikisine de mesafeli olabilmeyi gerektirir. Bu anlamda melez kimlik her iki kültüre de kuşku ile yaklaşırken, aynı biçimde her iki kültür için de kuşku üreten bir durumdur. O halde bu durum, aidiyet hissi, deneyimler, çıkarımlar, kabuller ve redlerle bireyin oluşturacağı bir süreçtir ve heterojen bir yapıya sahiptir.

Bu heterojen yapı içinde birey kendi dilini de kendi oluşturabilir. Tıpkı bu romanda olduğu gibi bazı duygulanımlarını Quechua dilinde bazılarını da İspanyolca dilinde ifade edebilir. O, her durumda kendi için kendine uyumlu olanı seçebilir ve durum değiştikçe seçimleri değişebilir. Ancak bunu yaparken dil ve kültür arasındaki ilişkinin öncelikle doğal ve sağlıkı kurulması, bunu gerçekleştirmek için de ayrımcılığın her türlü biçimiyle mücadele edilmesi gerekir. Bilindiği gibi, Arguedas'ın bütün hikaye, roman, makale ve konuşmalarını bu görüş temellendirir. Arguedas bu görüşe yaşamını ve yazınını adadı. İntiharından kısa bir zaman önce, Inca Garcilaso de la Vega ödülünü kazandığında, belki bilerek belki de farkında olmadan yaptığı veda konuşmasında, Avrupa kültürüne yakınlı̆̆ı oranında "kültürlenmiş" bir kişi olmadığını özellikle belirtecek ve "mutlu bir iblis gibi" gururla hem hristiyanın hem yerlinin dilini, İspanyol ve Quechua dilini konuşan bir Perulu olduğunu, sadece bu yalın gerçekliği sanatsal dile dönüştürmek istediğini ve aşağı yukarı genel bir fikir birliğine göre başardığı için de Inca Garcilaso de la Vega ödülünü sevinçle kabul ettiğini söyleyecektir. Bu konuşmada, Arguedas, başlangıçtan beri arzuladığı bu idealini gerçekleştirmeye çalışırken itici güç olan iki temelden söz eder. Öncelikle, ait olduğu iki halkın birbiriyle çatışma içinde olmasının, gençliğinden beri içinde hissettiği isyana; mücadele etme, bir şeyler yapma arzusuna neden olduğuna işaret eder. Bu düzlemde, ilk temeli, "içindeki büyülü yanı öldürmeyen” sosyalist teori oluşturacaktır. Mariátegui ve daha sonra Lenin'i okuyarak kalıcı bir düzen bulduğunu; sosyalist teorinin yalnızca tüm geleceğe değil, içindeki enerjiye de bir kanal oluşturduğunu belirtir; ona bir kader vermiş ve onu yönlendirme işlemiyle daha da güçlü kılmıştır. Asla bir politikacı gibi davranmadığını, bir parti disiplinini uygulama yeteneğine de sahip olduğuna inanmadığını belirtirken gençlik dönemi boyunca zincirinden boşaldığını hissettiği enerjiye net bir hedef, yön ve kalıcllı verenin, sosyalist ideoloji ve sosyalist hareketlere yakın olmak olduğunu

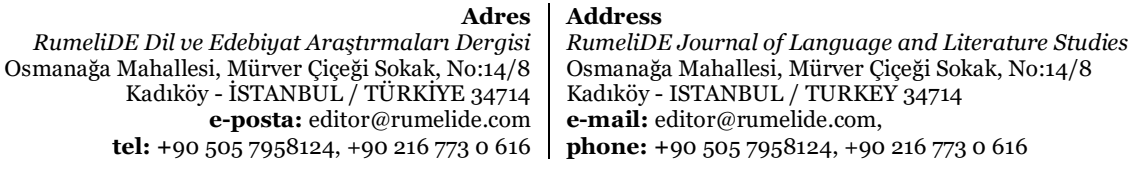


vurgular. Arguedas'ın sözünü ettiği diğer temel, ısının ve rengin, aşkın ve nefretin, çarpıklıkların ve inceliklerin bütün derecelerini gösteren bu ülkeyi, Peru'yu, her zaman yaratı için sonsuz bir kaynak olarak görmesi ve öğrendiği her şeyi bu ülkeyi anlamanın bir yolu olarak değerlendirmesidir (Arguedas: 2006, 13-14).

Bu düzlemde, José Marīa Arguedas'ın bütün yaşamı boyunca sürdürdüğü bireysel mücadele, toplumsal mücadeleden ayrı düşünülemez, $O$, sosyalizmi yerli duyarlı̆̆ıyla örtüştürmüş, içsel enerjisini, duygularını, bireysel söz, ilke ve değerlerini toplumsal ve tarihsel olarak da yapılandırabilmiştir.

$\mathrm{Bu}$ duruşuyla, Peru ve Latīn Amerika Yerli mücadelesinden de ayrı değerlendirilemez, aksine, bu mücadelenin ayrılmaz bir parçasıdır: o dönemde, ülkenin merkezi ve Güneyi -romanın ilk bölümlerinde hikayenin başladığı Cuzco kentinin de içinde bulunduğu bölge- Yerli halkın yoğunlukla yaşadığı yerlerden biri haline gelir. Carlos Contreras ve Marina Zuloaga, Historia Mīnima de Perú başlıklı ortak çalışmalarında, bu bölgenin "yerli lekesi” olarak adlandırılmaya başlandığını, yerli nüfusun, bu ibareyle, egemen sınıf için bir "sorun" olarak değerlendirildiğinin bir göstergesi olarak kavramsallaştırıldığını, metaforik olarak beyaz'ı 'kara'yı yıkayıp, lekeyi temizleyeceği anlamını taşıdığını belirtir. Yine aynı düzlemde yerli nüfusun iş, eğitim ve hijyen yoluyla da temizlenmesi/kurtarılması gerekiyordu. Bu da onları bir bakıma düzeltmek, kapitalist bir toplumda iyi işçilere dönüştürmek anlamına geliyordu. Yine aynı çalışmada, yerli nüfusun beyaz kültüre yakınlaştırılması, kentleşmesi ve 'kültürlenmesi' planlarına bir tepki olarak, yerlilerin kendi kültürlerini savunmalarının 1920'lerde ortaya çıktığını, bu durumun Yerli kültürü yücelten bir kent hareketi olarak değerlendirildiği belirtilir. (Contreras, Carlos ve Marina Zuloaga, 2014: 236). 1920'den bu yana geçen süreçte, Peru Devleti, Yerli topluluklarını yasal olarak tanır: yirmili ve altmışlı yıllar arasında, varlıkları ve özellikle toprakları konusunda özel bir koruma statüsüne sahip olan 1500'den fazla yerli topluluk resmi olarak tanınır (Contreras, Carlos ve Marina Zuloaga, 2014: 237).

Nelson Osorio Tejada Arguedas'ın kendi özelinde ve melez kimlik üzerinden sürdürdüğü toplumsal mücadeleyi şu cümlelerle ifade ediyor: "José Marīa Arguedas buydu/budur. Halkı için bir ifade arayışı içinde olan, Quechua ve İspanyolca'yı küçümsemeden, "tüm kanların", umutların gerçek olduğu bir dünya düşüne doğru akmasına izin veren bir yazınsal dil yaratan, icat eden, inşa eden iki dilli bir melez" (Tejada, 2012: 80).

José Marīa Arguedas, ikidilliliğini kendi doğasının bir parçası olarak gördüğünden, yaşamında olduğu ölçüde, yazınında da İspanyol ve Quechua dilini kullanır. Aynı zamanda şair olan yazar, şiirlerini Quecuha dilinde yazmayı tercih eder. Romanlarında da daha çok halk şarkılarında ve duygularını ifade ederken bu dili kullanır. Bu seçim, onun zihinde ve ruhunda her iki dille kurduğu ilişkinin doğal yansıması bu durumunun basit bir biçimde dışavurumudur.

Garcīa Morales Ortiz, "La influencia de lo quechua en la narrativa de Arguedas: Un acercamiento a sus relatos” başlıklı çalışmasında, Arguedas'ın bütün yapitlarında İspanyolca ve Quechua dilini nasıl biçimsel ve anlamsal olarak birbirine dönüştürdüğünü açlklarken, sözel kültürde var olan Quechua dilinin belirleyici özeliklerini bozmadan İspanyolca’ya aktardığının, dolayısıyla yapılan işlemin basit bir biçimde İspanyolca'yı 'quechualılaştırmak' olmadığının, sadece sözel kullanımın ürettiği mekanizmaları bulmak ve onları yerli iletişim tarzına yaklaştırmak olduğunun altını çizer. Bu yüzden, "bu şarkılarda, Batı bakış açısına uyarlamaya gerek kalmadan, yerli toplumunun düşüncesinin doğrudan yansıtıldığını" belirtir. (Ortiz, 2012: 54-55).

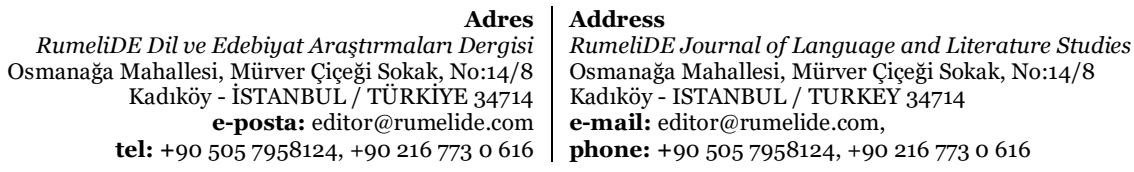


The attempt to re-create mixed race identity in the novel Los Rios Profundos by the Peruvian author José Maria Arguedas / O. Öztunalı (pp. 1211-1220)

Bu romanda da çocuk kahraman Ernesto, daha çok doğa ile iletişime geçtiğinde, duygulandığında ya da okulda babasını özlediği zamanlarda Quechua dilinde şarkılara sığınır. Dil ve kültür arasındaki bağlantı romanda çok bütünlüklü bir biçimde işlenmiştir. Quecuha dili Yerli kültürün doğayla olan ilişkisini, kozmik bütünlüğü ve evrensel birliğini duyumsatır. Doğa, kültür, insan aynı süreçte buluşur. Örneğin nehrin sesi, insanın bireysel yaşamı ve Yerli toplumun tarihine dönüşür. Doğayla yapılan meditasyon öncelikle insanın kendi içinde bir uyum, sonrasında da evrenle bir birlik duygusu yaratır. Peru'da, İnka kültüründen günümüz yerli kültürüne miras kalan doğayla kurulan bu iletişim sayesinde Ernesto yatılı okulda geçirdiği zorluklarla dolu yılların acısını hafifletir. Müzik bazen günlük hayatın dayanılması güç çatışmalarına çözüm olarak, Ernesto'nun başvurduğu bir çare olarak ortaya çıkar. Okulda bir arkadaşının hediye ettiği Quecuha dilinde 'zumbayllu' adı verilen topaç sayesinde mistik bir biçimde geçmişiyle iletişim kurar:

"Zumbayllu'nun şarkısı kulağa girer, ırmakların, uçurumların duvarlarında asılı kara ağaçların görüntüsünün hatırasını canlandırırdı.” (Arguedas, 1998: 242)

(El canto del zumbayllu se internaba en el oỉdo, avivaba en la memoria la imagen de los rios, de los árboles negros que cuelgan en las paredes de los abismos”.)

Yine aynı düzlemde, Claudia Macias Rodrīguez, "Palabra y mito en Los rīos profundos" başlıklı makalesinde, yerli kültürün geçmişini unutmamasında belleğin önemini ve müziğin hafızayı açmak gibi aşkın bir işleve sahip olduğunu belirtirken, bu doğrultuda "zumbayllu"nun işlevinin belleği harekete geçirmek olduğunu vurgular (Rodriguez, 2009).

Bu anlamda onun yaydığı müzik, yerli kültürün doğa ile iletişimde kurduğu illahi sesi, hareketi, şiirselliği temsil eder. Bu yüzden 'zumbayllu' bu romanda evrensel barışın simgesi olarak kabul edilir. Ancak diğer taraftan, daha genel anlamda, insanoğluna zihinsel alanın, beşeri dilin dışındaki kadim bilgiyi iletir. Herrea Montero'nun “La heterogeneidad en los rīos profundos de José Marīa Arguedas” başlıklı makalesinde bu durumu aşă̆ıdaki sözcüklerle ifade ediyor:

\begin{abstract}
“Arguedas'ın romanında, kelime, kavranabilecek her şeyi istila etmek için beşeri olanın ötesine geçer. Dünyanın ve nesnelerinin kendi dilleri vardır: konuşurlar, şarkı söylerler ve bunu yaparken karanlık anıları uyandırırlar, insanın gözlerine aynı zamanda hem görünür hem de görünmez olan bir dünyanın iradesini ve gücünü aktarırlar. Örneğin nehirler, taşlar ve adalarla çarpışırken en güzel müzikle şarkı söyler. Sesi insanların hafizasına nüfuz eder, kaderlerini etkiler, olayların gidişatını belirler.” (Herrera Montero, 2009: 13)
\end{abstract}

Bu doğrultuda, roman boyunca doğa ve onun bütün unsurları Quechua dilinde söylenen geleneksel yerli şarkıları üzerinden 'dile gelirler'. Arguedas gibi, Ernesto için de Quechua dili anlamını şarkıda, şiirde, sözel kültürün ağızdan ağıza söylenerek günümüze kadar gelmiş hikayelerinde bulur. Bu hikayeler kimseye ait değildir. Ama aynı zamanda herkese aittir; toplumun ortak paydasıdır. Halk bu hikayeler, şarkı ve şiirlerle toplumsal belleğinde geçmişini korur, sürekli tekrarlayarak bir sonraki kuşaklara devreder. Ben değil biz bilinci vardır. Bu hikayelerde zaman da Avrupa kültünde olduğu gibi doğrusal değil döngüseldir, tıpkı doğa ve doğa olayları gibi. Bu anlamda yerli kültürün tarihi, bir nehrin, bir taşın, bir dağın zamanına da sinmiştir. Çünkü yerli için doğa ve kültür karşıtlık değil birlik oluşturur. Oysa yazılı kültürle birlikte bireysel bakış açısının, yazar ve okur ayrımının, ortaya çıkmasıyla birlikte bu uyum bozulmuş, o zamana kadar herkese ait olan doğayla yine o zamana kadar herkese ait olan kültürün arası yavaş yavaş açılmıştır. Ernesto'nun içinde yetiştiği yerli kültürüyle, Avrupa kültürü arasında çocuk zihinde yaşadı̆̆ı en büyük kırılma budur. Roman boyunca farklı metaforlarla değişik biçimde işlenecek olan bu durum daha ilk bölümde, Ernesto'nun babasiyla birlikte geldiği Cuzco'da İnka surunun karşısındaki tutumuyla karşımıza çıkar:

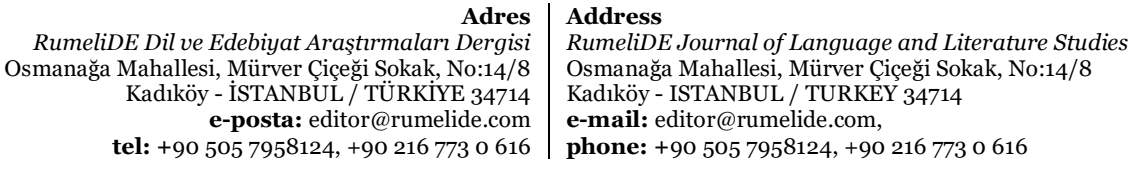

RumeliDE Journal of Language and Literature Studies

Osmanağa Mahallesi, Mürver Çiçeği Sokak, No:14/8

Kadıköy - ISTANBUL / TURKEY 34714

e-mail: editor@rumelide.com,

phone: +90 505 7958124, +90 2167730616 
“Taşlara ellerimle dokundum; dalgal,, öngörülemez çizgiyi takip ettim Kaya bloklarının birleştiği nehirlerinki gibi” (Arguedas:1998, 143)

("Toqué las piedras con mis manos; segui la līnea ondulante, imprevisible, como la de los rīos, en que se juntan los bloques de roca")

Nehirler, halkının tarihidir. Ve bir yerli parmak uçlarıyla tarihine dokunabilir. Ernesto, nehirle birlikte çocukluğunda halkının sürekli söylediği şarkıları hatırlar. Nelson Osorio Tejada’nın aynı makalede belirttiği gibi, bizim "şiir" dediğimiz, yerli halklar için sözdür, müziktir ve dansta formüle edilmiş duygudur. Başka bir deyişle, yerli kültürlerde şiir okunmaz, şarkısı söylenir dansı edilir (Tejada, 2012: 77).

“O zaman, sürekli dokunaklı bir cümleyi tekrarlayan Quechua şarkılarını hatırladım: yawar mayu, kan ırmağı; yawar unu, kanlı su; puk-tik'yawar k'ocha, kaynayan kan gölü; yawar wek'e, kanlı gözyaşları. Acaba yawar rumi, kan taşı ya da puk'tik yawar rumi, kaynayan kan taşı denilemez miydi? (Arguedas:1998, 144)

("Me acordé, entonces, de las canciones quechuas que repiten una frase patética constante: "yavar mayu", rio de sangre; "yawar unu", agua sangrienta; "pu'tik'yawar k'ocha”, lago de sangre que hierve; yawar wek'e", lagrimas de sangre. Acaso no podría decirse "yawar rumi", piedra de sangre, o "puk'ik'yawar rumi”, piedra de sangre hirviente?”)

Lucía Herrera Montero, "La heterogeneidad en los rios profundos de José Mara Arguedas” başlıklı makalesinde, Ernesto’nun İnka kültürünün sembolü olan İnka surunun karşısında Quecua dilinde söyenen bu şarkılarda sürekli tekrarlanan nakaratları hatırlamasının önemini vurgular. Bu nakaratlarda yerli halkın tarihi ırmağın suyunun akışıyla özdeşleştirilir. Romana da adını veren ırmak metaforu ve onun bazen kanlı, yoğun, şiddetli bazen de duru ve sakin akışı ile yerli halkın geçmişi, kaderi anlatılır. Böylelikle arkaik dönemlerde olduğu gibi modern edebiyatta da yaşamı simgeleyen su imgesinde tarih, doğa ile örtüşürken, suyun sesi de şarkılara dönüşür. Herrera Montero'nun da belirttiği gibi, şarkılar bir yandan gelenekle, diğer yandan da kendi içindeki çatışmalarıyla birlikte tarihle kesişiyor. Onlar bize geçmişin şimdiye nasıl dönüştüğünü en kısa yoldan anlatırken aynı zamanda yerli kültürün ortak belleğine sağlam bir zemin oluşturuyor: ataların mirasıyla yeniden bağlantı kurma, yerli toplumunun neredeyse efsanevi kimliğini koruma ve aynı zamanda romanda anlatı düzleminde yer alan tarihi olayları yeniden sunma işlevini görüyorlar. Ancak Herrera Montero'nun da belirttiği gibi, Yerli toplumunun tarihini ve aynı zamanda yaşamı simgeleyen su imgesinin karşısında, İnka surlarının üstünde yükselen İspanyol duvarı bir yandan sömürgecinin gücüne, diğer yandan da mimari bir düzen içinde toplumsal hiyerarşiye işaret ediyor (Herrera Montero, 2009: 17-18). Böylelikle, yerli kültürüyle doğayı buluşturan ırmak metaforundaki uyum, İnka surunun üzerine inşa edilen ‘beyaz adam’ın ördüğü duvarın varlığı ile ayrımcıllğa dönüşüyor.

Ricardo González Vigil’in Los rios profundos romanının önsözünde belirttiği gibi, Arguedas doğal düzenin bilgeliğine ve ancak söz konusu doğal düzene uyum sağlamış bir kültüre inanır (Arguedas:1998, 92-93). Bu anlamda doğa kültür çatışması, doğanın üzerine inşa edilmiş beyaz adamın mimarisiyle örneklendirilerek roman boyunca karşımıza çıkar. Bu görsel tezatlık, öncelikle iki kültürün birbiriyle çatışmasını, diğer taraftan da melez kimliğin kendi içindeki çatışmalarını gösterir. Kuşkusuz aynı zamanda hikayenin arka planına tarihsel gerçekçiliği yerleştirir. Ernesto'nun bireysel tarihinde yaşadığı şaşkınlık anlarının arkasında Latin Amerika tarihinde yaşanan, Yerli halk için beklenmedik, çok boyutlu kültürel dönüşümlerin kilit noktaları vardır. Örneğin Ernesto'nun, Cuzco'da, hayatında ilk defa bir katedral gördüğü an gibi. Ernesto, İnka taşları ve yerlilerin işçiliğiyle 'beyaz Adam'ın yaptırdığı bu katedrali şu cümlelerle betimler:

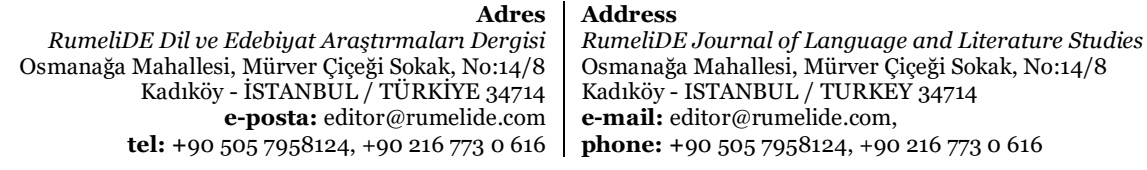


The attempt to re-create mixed race identity in the novel Los Rios Profundos by the Peruvian author José Maria Arguedas / O. Öztunalı (pp. 1211-1220)

\begin{abstract}
"Muazzam bir cepheydi; bazı yüksek göllerin kıyılarından yükselen dağların tabanı kadar geniş görünüyordu.” (Arguedas, 1998: 149)

("Era una inmensa fachada; parecia ser tan ancha como la base de las montañas que se elevan desde orillas de algunos lagos de altura.”)
\end{abstract}

Burada Ernesto, öncelikle melez bir çocuğun duru görüsüyle her iki kültürün kendi içinde ve kendine özgü bir biçimde duyumsadığı kutsiyet algısını, tarihin bütün karmaşıklı̆̆ına rağmen ayrım gözetmeksizin her iki kültürde de algılamaya çalışır. Diğer taraftan, Argüedas'ın büyük bir ustalıkla okura da geçirmeyi başardığı bu algı, Ernesto’nun bu duru görüsü, tıpkı İnka surunun üzerine inşa edilmiş 'beyaz adam'ın duvarı gibi, 'beyaz adam'ın İnka taşlarıyla yaptırdığı katedralin temsil ettiği hiyerarşik gücü daha da görünür kılar. Ama her şeye rağmen, Arquedas'ın burada vurgulamak istediği bütün hiyerarşik yapılanmaya rağmen, kutsal olanın duyumsanmasının her kültürde aynı olduğudur. Bütün kültürlerin eşitlendiği bu ortak payda, ancak tarihsel şiddete, zorbalıkla elde edilmiş kültürel dönüşüme son verdiren bir bakış açısıyla açığa çıkacaktır.

Toplumun inanç düzleminde maruz bırakıldığı kültürel dönüşüm, eğitim düzleminde okul metaforuyla yine karşımıza çıar. Ernesto'nun dini bir okula yatılı bir öğrenci olarak kaydolmasıyla birlikte, 'beyaz adam"ın sömürgeci bakış açısını daha yakından tanıma olanağı buluruz. Ernesto yeni inanç sisteminin beraberinde getirdiği yeni eğitim sistemine, bu sistemin kurallarına, hiyerarşik ilişkilerine de yabancıdır ama burada tanık olduğu ve maruz kaldığı adaletsizliğe, şiddete, iki yüzlülüğe ve her türden ayrımcıllğa karşı tek başına dayanmak zorundadır. Gustavo Martỉnez, Ernesto’nun pek çok şiddete tanıklık edeceği okul avlusunu bir tür mikrokozmos olarak algılar: Bu alan Martinez’e göre bütünüyle bir yozlaşma alanı olarak değerlendirilmelidir (Martīnez, 2008-2009: 45).

Donald L. Shaw'ın belirttiği gibi, Arguedas sadece üç yaşındayken annesi ölür ve o üvey annesinin bulunduğu evde, mutfakta yerli hizmetlilerin yanında büyür ve Abancay'da dini bir okula yatılı olarak girer (Shaw 71). Ernesto'da aynı kaderi paylaşır. Babası ile yatılı okula kayıt olmak için büyük şehre geldiklerinde kendilerine ayrılan oda, yerlilerin kaldığı hizmetçi odasıdır:

"O odada kendimi kötü hissetmedim. Çocukluğumda beni yaşamaya zorladıkları mutfağa çok benziyordu; yerli hizmetçilerin ve "cocertado"'ların ilgisini, müziğini, şarkılarını ve tatlı konuşmalarını aldığım karanlık odaya” (Arguedas, 1998: 142-143)

("Yo no me sentia mal en esa habitación. Era muy parecida a la cocina en que me obligaron a vivir en mi infancia; al cuarto oscuro donde recibì los cuidados, la música, los cantos y el dulcisimo hablar de las sirvientes indias y de los "cocertados")

Ernesto'nun kendini kötü hissettiği yer o oda değil, aksine, beyaz ırktan bir babanın oğlu olma sifatıyla kayıt olma hakkı kazandı̆̆ı okuldur. Okulda, burjuva iki yüzlülüğüne, din, dil ırk, cinsiyet ayrımcılığına, fiziksel güç ile toplumsal, ekonomik statü hiyerarşisine dayalı katlanılması zor olaylara tanık olur. Yerli mahallelerindeki yoksulluğu, sefaleti görmek, üstelik de sömürgeci kültürün içinden, sömürgecinin gözüyle nasıl değerlendirildiğini bilmek, başka bir deyişle, şehirde onların insan yerine konulmadığını görmek Ernesto'nun ruhunda derin bir elem, huzursuzluk ve karmaşa yaşatır.

Gustavo Martīnez, "okulda nefretin sonu gelmez” derken çatışmanın ve şidddetin sürekliliğine dikkat çeker ve Ernesto'nun asıl okulunun 'doğa' olduğunu vurgular. Doğada ne duvarlar ne avlular vardır. İçinde fakir yatıllılar veya geleceğin mal sahipleri yoktur. Hiç kimse önemsiz değildir çünkü herkes yaşamın tükenmez akışında dayanışma içindedir (Martīnez, 2008-2009: 55).

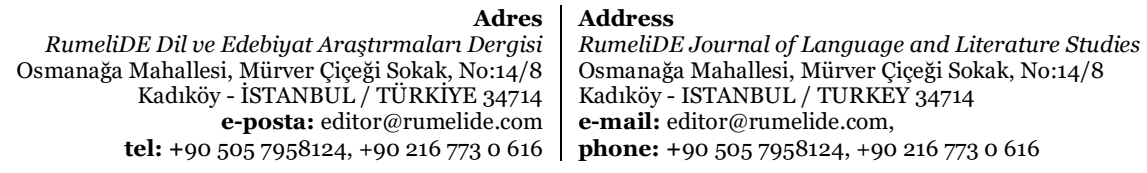


Bu anlamda, José Miguel Oviedo, Arguedas'ın romanında her iki kültürün bütün uyuşmazlığına, bütün gerginliğine rağmen her iki dünyayı birleştiren ince ipliğin hiç kopmadığını ifade eder; bu iplik asla kopmaz ya da gerginliğini kaybetmez (Oviedo, 2001: 80). Başka bir deyişle iki dünya arasındaki bu gerginlik roman boyunca sürekliliğini korur.

Aynı düzlemde, Miguel Alvarado Borgoňo göre, bu romanda şiddet, kültürel sentezin var olmadığının işareti olarak kullanılır: Arguedas'ın bu romanı, kurgusal türün, görünüşte homojen, ancak iç yapısında farklı bir tür melez metin içinde yeniden yorumlanmasını temsil eder. Kültürel sentezin var olmadığının en açık biçimde ifadesi, bir anlaşmazlık metaforu olarak şiddettir, bu nedenle Borgoño'ya göre bu romanda şiddet patoloji değil, işaretlerin yeniden doğrulanmasıdır (Borgoňo, 1998).

Şiddetin varlığı çatışmanın olduğunun kabulüdür. Başka bir deyişle çatışmayı yaratan tarafların varlığının kabulüdür. Bu anlamda roman baştan sona çatışma üzerine kurulur: inançlar arasındaki çatışma, değerler arasındaki çatışma, diller arasındaki çatışma, doğrusal zamanla döngüsel zaman arasındaki çatışma, kutsal doğa ile kutsiyetini yitirmiş dış gerçeklik arasındaki çatışma, bireysel alan ile toplumsal alan arasındaki çatışma. Ve her birinin kendi içinde açılan/ açılagelen yeni çatışma alanları. José Marīa Arguedas bunların hiçbirini reddetmez. Roman boyunca bunların hiçbirine çözüm de getirmez. Sadece melez kimliği yeniden oluşturma çabasında bütün bu çatışmaların hepsinin varlığını kabul eder. Çünkü ancak bu kabulle, melez kimlik kendini yeniden oluşturma çabasına girer.

\section{Sonuç}

Roman boyunca, melez kimliği oluşturma sürecinde, çocuk kahraman Ernesto'nun Cuzco'da başlayan Abancay'da bir yatılı okulda devam eden sancllı hikayesine tanık olduk. Ernesto'nun, José Maria Arguedas gibi ergenlik çağında aidiyet duygusunu geliştirirken, farklı iki dil, birbiriyle uyumsuz sürekli çatışan iki kültür arasında kalışını gözlemledik. Her ikisinin de benlik ve kimlik gelişiminde, hayatı anlamlandırma ve hayata karşı değer oluşturmada yaşadıkları zorlukların başında, iki kültür arasında eşitlik ilkesine dayanmayan, 'daha gelişmiş' olanı 'daha az gelişmiş' olandan üstün kabul eden ve varsayılan bu üstünlüğü eline geçirenin diğeri üzerinde dayattığı zorlayıcı entegrasyon sürecinin bireyler ve toplumlar üzerinde, nasıl kırıklıklar yarattı̆̆ını saptadık. Roman boyunca, yerli ve beyaz kültürün her ikisine de belli bir mesafeden bakan melezlik durumunun, bu iki kültürün birbirleriyle uyuşmayan çatışmalarının, dil farklılıklarının, evreni ve doğayı algılama ve değerlendirme biçimlerininin değişik metaforlarla nasıl temsil edildiğini anlamaya çalıştık. Arguedas'ın, tarihsel süreç içinde kültürel bütünlüğünü kaybetmiş olan melez kimliği yaşamında ve yazınında yeniden oluşturmaya çalışırken, öznel ve toplumsal alanda çatışma yaratan durumları, Ernesto üzerinden büyük bir içtenlikle ortaya koyma ve 'duyurma'çabasına tanıklık ettik. Bu anlamda, roman boyunca öznel olanla toplumsal olanın, bireysel tarihle Peru tarihinin birbirine denk düştüğünü gözlemledik. Bu süreçte yaşanan çatışmalara Arguedas'ın bir çözüm getirmediğini saptadık. Çözümün ancak her iki tarafın birbirinin varlığını kabul etmesiyle gelişen doğal iletişimin kendisi olduğunu, bu anlamda, roman boyunca işlenen çatışmanın, en azından tarafların varlığının kanıtı olarak da değerlendirilebileceğini gözlemledik. Barışa giden yolun, Arguedas'ın yaşamında ve romanında ancak eşitlik, kardeşlik duygusu ve yapıcı yaratıyla beslenen bir yöntem olarak sunulduğunu belirledik.

\section{Kaynakça}

Arguedas, José Marīa. (1998). Los rīos profundos, Madrid: Catedra, (Ed. Ricardo González Vigil).

Arguedas, José Marīa. (1967). “El İndigenismo en el Peru”, Clásicos y Contemporáneos en Antropologia, CIESAS-UAM-UIA Tlatoani, Vol.18.

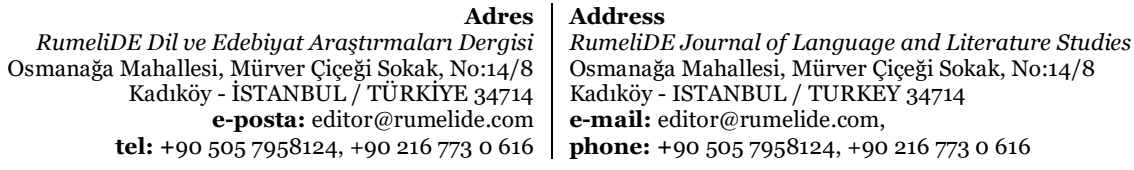


http//:www.ciesas.edu.mx/Publicaciones/Clasicos/Index.html. (25.01.2021)

Arguedas, José Maria. (2006). "No soy un aculturado", El zorro de arriba y el zorro de abajo. Caracas: Fundación Editorial el perro y la rana, https://laburla.files.wordpress.com (26.06.2021)

Borgoňo, Miguel Alvarado. (1998).El sueňo de la comunicación en José Marīa Arguedas: Lecturas de los Rïos Profundos, Literatura y Lingüistica,.11, 139-163, Santiago, 1998. http://dx.doi.org/10.4067/So716-58111998001100012 (27.01.221)

Contreras, Carlos ve Zuloaga, Marina. (2014). Historia Mīima de Perú. Espaňa: Turner Publicaciones.

Ortiz, Garcia Morales. (2012). La influencia de lo quechua en la narrativa de Arguedas: Un acercamiento a sus relatos. América sin nombre. No:17, pp. 47-58.

Herrera Montero, Lucia. (2009). La heterogeneidad en los rios profundos de José María Arguedas. Colección de Filosofia de la Educación. N 6, 11-25

Martinez, Gustavo. (2008-2009). Espacio, identidad y memoria en Los rios profundos. Humanidades Aňo VIII-IX, N 1, Diciembre,.43-58.

Oviedo, José Miguel. (2001). Historia de la literatura hispanoamericana 4. De Borges al presente, Madrid: Alianza.

Rodrīguez, Claudia Macias. (2009). Palabra y mito en Los rīos profundos. Espéculo. Revista de estudios literarios. Universidad Complutense de Madrid, http://www.ucm.es/info/especulo/numero41/riosprof.html (26.01.21)

Shaw, L. Donald. (1999). Nueva Narrativa Hispanamericana, Madrid: Cátedra.

Tejada, Nelson Osorio. (2012). José Marīa Arquedas y el lenguaje de la identidad mestiza. América sin nombre. N 17, 75-80, https://americasinnombre.ua.es (7.05. 2021)

RumeliDE Dil ve Edebiyat Araştırmaları Dergisi Osmanağa Mahallesi, Mürver Çiçeği Sokak, No:14/8 Kadıköy - ISTANBUL / TÜRKIYE 34714 e-posta: editor@rumelide.com tel: +90 505 7958124, +90 2167730616
Address

RumeliDE Journal of Language and Literature Studies Osmanağa Mahallesi, Mürver Çiçeği Sokak, No:14/8

Kadıköy - ISTANBUL / TURKEY 34714

e-mail: editor@rumelide.com

phone: +90 $5057958124,+902167730616$ 